\title{
¿ADÓNDE VAN LOS EDIFICIOS CUANDO MUEREN?
}

\author{
WHERE DO BUILDINGS GO WHEN \\ THEY DIE?
}

\author{
ANAEL RODRÍGUEZ FERRARI \\ Universidad de Lima \\ orcid.org/0000-0002-7060-3064
}

El presente artículo plantea entender la arquitectura desde una perspectiva circular, lo que implica el manejo de estrategias de reutilización o reabsorción natural de los componentes que la conforman para evitar así la "muerte" del edificio, traducida en una demolición ineficiente al final de su vida útil. El problema se aborda desde dos diferentes propuestas: la arquitectura biodegradable, que cierra el ciclo energético regresando sus componentes a la tierra; y la arquitectura del desensamble, pensada en piezas para proporcionarle una segunda vida a los componentes de construcción. El contraponer estas dos posturas, lo "artesanal" y lo "industrial", muestra distintas maneras de perseguir la sostenibilidad en el entorno edificado.

vida útil, edificación, circularidad, arquitectura biodegradable, desensamble
CAROLINA NEUHAUS BUZAGLO

Universidad de Lima

orcid.org/0000-0002-2780-2316

Recibido: 3 de julio del 2020

Aprobado: 12 de septiembre del 2020

doi: https://doi.org/10.26439/limaq2021n008.5550

This article proposes a circular perspective to understand architecture, which means that the design process must keep in mind the reuse strategies at the end of the life cycle, in order to avoid its "death": an inefficient demolition of the building. We approach the problem from two different viewpoints: biodegradable architecture, in which the natural components follow the natural flow and return to the system by their degradation into nature; and design for disassembly, in which the building's components are dismantled in order to be reused. The article argues that it is possible to explore new ways of pursuing sustainability in the built environment by opposing these two perspectives.

useful life, edification, circularity, biodegradable architecture, disassemble 


\section{INTRODUCCIÓN}

¿Es el tiempo de vida de una edificación indicador único de su sostenibilidad? ¿Qué sucede cuando los edificios se vuelven obsoletos? Son preguntas que rara vez se conciben desde el inicio del proyecto, puesto que con un optimismo irrealista se entiende el edificio como un objeto eterno y monolítico, en el que no se suele contemplar adónde irán a parar sus componentes cuando este haya llegado al final de su vida.

Sin embargo, el mundo de hoy exige pensar en el medio construido desde una perspectiva cíclica, tal como lo ha hecho la tierra por millones de años. Las circunstancias requieren evaluar el ciclo completo de vida del edificio y proponer estrategias que respondan al final de su vida útil, cuando no haya lugar para los desperdicios. Llegar al punto de la demolición debería ser considerado una falla en el diseño.

En el Perú la principal estrategia de fin de ciclo de un edificio es la demolición, la generación de desmonte y, por lo tanto, residuos. En el año 2012, los sectores manufactura y construcción fueron responsables de la emisión de 9386200 toneladas de dióxido de carbono al medio ambiente (Ministerio del Ambiente, 2012b). En relación con los desechos físicos oficiales, según la Cámara Peruana de la Construcción (CAPECO), en Lima Metropolitana se producen $30000 \mathrm{~m}^{3}$ de desmonte al día (como se citó en León, 2017). Sin embargo, ¿cuál sería la cantidad real de desmonte producido por la construcción si se incluyera el sector informal?

Esto nos lleva a preguntarnos adónde van a parar todos estos residuos. En el 2015, existían 1106 botaderos en el Perú, 26 de ellos en Lima Metropolitana (Ministerio del Ambiente, 2015). En el año 2012, se tenían registrados 12 botaderos autorizados, de los cuales 4 funcionaban en Lima (Ministerio del Ambiente, 2012a), dejando un porcentaje significativo de residuos sin un paradero autorizado. Según CAPECO, el $70 \%$ del desmonte de construcción va al mar, mientras el $30 \%$ se distribuye en puntos autorizados (como se citó en León, 2017).

En el Reglamento Nacional de la Construcción, el tema de la sostenibilidad se encuentra señalado en el Decreto Supremo 015-2015-VIVIENDA y en la norma EM.110, Confort Térmico y Lumínico con Eficiencia Energética (Norma EM.110, 2014). Ambas normas se enfocan en minimizar el consumo energético durante la etapa de uso. Si bien ambas implican un aporte positivo, no toman en consideración las distintas etapas del ciclo de vida de un edificio, siendo, además, de aplicación opcional.

Hasta ahora la mayor parte de los esfuerzos de los arquitectos e ingenieros se han enfocado en la etapa de uso. Esta representa entre el $70 \%$ y el $90 \%$ del consumo de energía durante el ciclo de vida del edificio, muchas veces relacionado con el uso de combustibles fósiles y emisión de gases que generan el efecto invernadero (Fay et al., 2000). Sin embargo, la extracción de materia prima, manufactura de materiales, su transporte y construcción, también contribuyen significativamente al deterioro del medio ambiente (Fay et al., 2000). 
Este artículo se centra en el "después" de la vida útil del edificio, enfocándolo desde una perspectiva circular y dejando de lado el sistema lineal: producirusar-desechar. $\mathrm{Al}$ analizar los componentes del edificio dentro de un ciclo cerrado, el problema se aborda a partir de dos posturas aparentemente divergentes: la arquitectura "biodegradable", aquella que cierra el ciclo energético regresando sus componentes al medio; y la arquitectura del "desensamble", pensada en proporcionar una segunda vida a los componentes de construcción. Antes de adentrarnos en los distintos escenarios de fin de uso, es importante entender en qué consiste el ciclo de vida de un edificio.

\section{LA VIDA ÚTIL DE LOS EDIFICIOS}

El término "vida útil" proviene de un ámbito ajeno a la arquitectura. Es una característica asignada a productos para determinar el tiempo que estarán en uso pleno antes de ser clasificados como inservibles. Al trasladar este concepto al medio construido, encontramos variables más complejas, ya que los indicadores de utilidad de una edificación no se limitan únicamente a los económicos. Esta maneja, además, factores físicos como la durabilidad de los materiales que la constituyen o el estado estructural de sus componentes; también factores sociales, tales como la asignación de valor cultural o su vigencia desde una perspectiva funcional y energética.

Existen diversos enfoques para determinar la vida útil de una edificación. En un primer grupo se incluyen las características físicas de sus componentes y cómo estos se mantienen en el tiempo. Algunos autores (Da Silva, 1998; Pérez, 2010) lo definen como el periodo de tiempo después de la construcción en el que, a pesar del mantenimiento rutinario, todas sus propiedades esenciales alcanzan o superan el valor mínimo aceptable.

Por otro lado, también se puede entender la vida útil desde una perspectiva económica, ligada a las fuerzas del mercado. Para Kotler y Armstrong (2003), el ciclo de vida de un producto (CVP) se encuentra marcado por las ventas y utilidades de este. Mientras que para Lamb et al. (2006) el ciclo de vida de un producto permite identificar las etapas de aceptación de este en el mercado, desde su inducción hasta su declinación. En ambos casos, el ciclo de vida se encuentra determinado por la oferta y la demanda, al igual que su obsolescencia.

Al entender un proyecto desde su sostenibilidad, se consideran tanto los materiales como su buen funcionamiento, ambos estrechamente ligados al manejo de aspectos ambientales, sociales y económicos (Thiébat, 2013). Bajo el criterio de "temporalidad durable", se busca garantizar la extensión del tiempo de uso, es decir, el tiempo de vida, a fin de lograr la sostenibilidad ambiental y social. Esto permite crear bienes útiles y económicamente sostenibles (Lavagna et al., 2014).

El tiempo de vida útil de un edificio es solo una parte de su ciclo de vida, comprendido desde el momento de su ejecución hasta el fin de uso (Pérez, 2010). Es necesario entender que un enfoque cíclico integrado considera al proyecto de diseño como el punto de inicio, pasando luego por la ejecución, 
Figura 1.

Ciclo de vida

circular

Elaboración propia uso, mantenimiento, reformulación y, finalmente, el regreso al ciclo (Miceli, 2016).

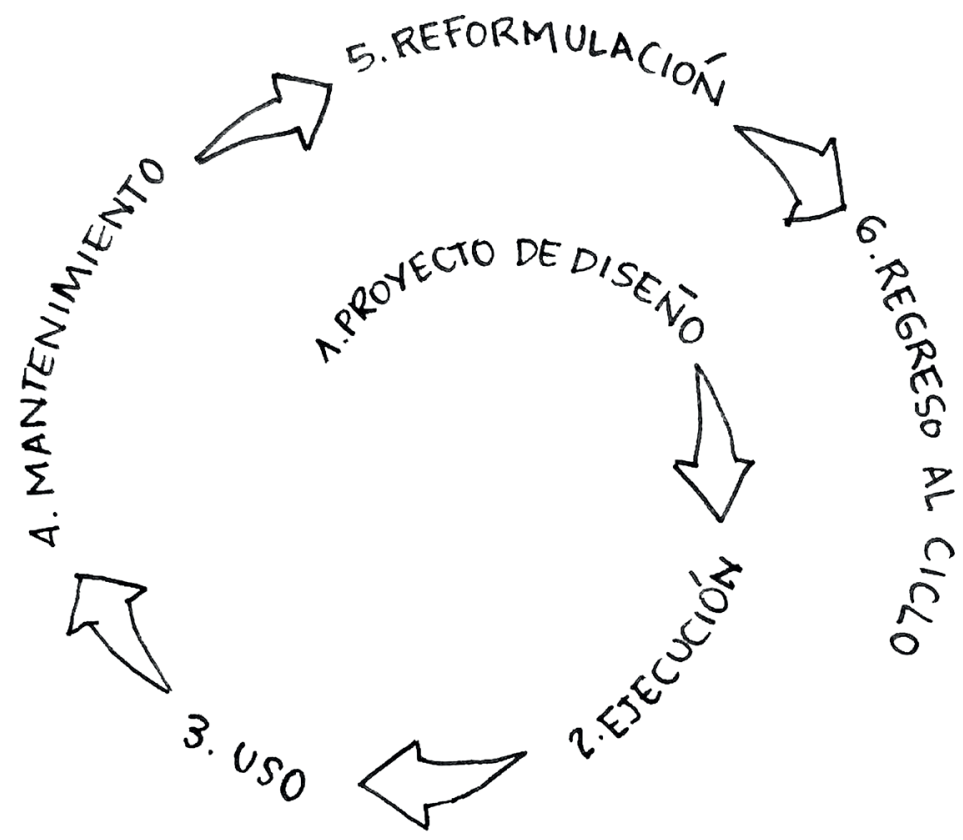

Esto se conoce como "evaluación del ciclo de vida" (life cycle assessment, LCA) y mide los impactos ambientales durante el ciclo de vida de la edificación (Fay et al., 2000). Fue definido por primera vez en la norma ISO/TC 207/SC en el año 1999 y actualizada en el 2006.

Así, el ciclo de vida del edificio se presenta como un proceso cíclico en el cual, una vez agotado su tiempo de vida útil, las estrategias de fin de uso garantizan una segunda vida para sus componentes (Organización Internacional de Normalización [ISO], 2006) o el regreso de estos al sistema. De esta manera, el fin de vida de un proyecto no es determinante, sino que conduce a una etapa de reformulación. Esta permitirá la adecuación de los materiales o de sus funciones para extender su vida útil o vuelta al ciclo.

Entendida la característica cíclica de un proyecto, ¿es posible definir el tiempo de vida útil de un edificio de manera cuantitativa? Según los objetivos del LCA, un edificio debe vivir de preferencia más de cincuenta años (Petrovic et al., 2019), y otros estudios sostienen que los impactos medioambientales de un edificio se minimizan al incrementarse su tiempo de vida, por lo que buscan determinar un tiempo mínimo ideal (Dodoo et al., 2009).

En el Perú, el Ministerio de Economía y Finanzas, en la Directiva 002-2014$\mathrm{EF} / 51.01$ (2014), analiza el tiempo de vida útil de un edificio en relación con las tasas de depreciación de los materiales que lo conforman. De esta manera, basa 
el tiempo óptimo de vida de un edificio en la durabilidad de sus materiales de construcción, aplicando tasas de depreciación sobre el predio. Esta directiva asigna un rango de vida útil de entre 50 a 80 años a edificios de concreto, ladrillo, acero o materiales equivalentes, y 33 años a materiales como el adobe, madera y quincha.

Sin embargo, estas afirmaciones resultan incompletas, ya que, bajo esa premisa, muchas edificaciones de adobe existentes en nuestro medio no cumplirían con los requisitos cuantitativos de tiempo de vida, incluso estando en condiciones aceptables. La Casa del Oidor, construida en el siglo Xvı, aún en pie, ha sido escenario de importantes hechos históricos, tales como la ovación al general San Martín luego de la proclamación de la independencia en 1821. Hacerla llegar al final de su vida útil, considerando únicamente factores económicos, sería negar parte de la memoria colectiva de un pueblo.

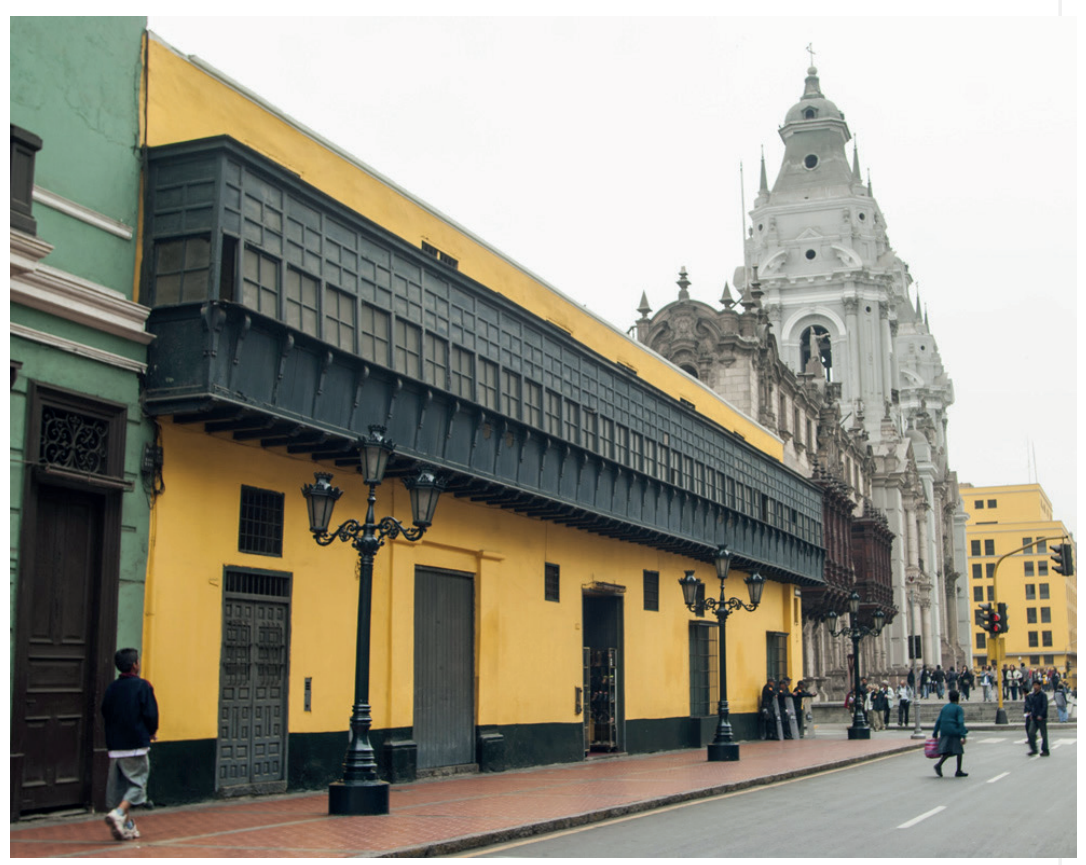

Es por ello que un cálculo aritmético del tiempo de vida útil de un edificio es una respuesta genérica, que no comprende la complejidad del medio construido. Este variará en relación con su contexto geográfico, la resistencia de sus materiales, el consumo energético, los gastos de mantenimiento, el tipo de uso, su flexibilidad funcional y el valor cultural que haya alcanzado en su medio. Asimismo, el cálculo variará si se analizan los componentes por separado o el edificio como unidad, y dependerá de su capacidad de adaptarse a las nuevas tecnologías y necesidades (Thiébat, 2013).

Lo que es definitivo es que tarde o temprano el fin de la vida de la edificación llegará y es entonces cuando se deben tener claras las estrategias a seguir. En 
inglés se utiliza el concepto de end-of-life (EOL) para determinar el momento en que un producto o edificio ha agotado su tiempo de vida funcional (Kwak et al., 2009). En un sistema lineal, sin estrategias de término cíclico, esto significaría su demolición.

A pesar de los grandes beneficios que implica pensar la arquitectura como un sistema circular, aún son pocos los edificios diseñados contemplando su capacidad de adaptarse al cambio o de reusar sus elementos (Denis et al., 2018). La aplicación de las distintas estrategias de reutilización, reciclaje del material, reciclaje energético o de desechos útiles tiene el potencial de cambiar la manera de concebir el proyecto arquitectónico (Kwak et al., 2009).

Entender el fin de la vida del edificio como un inicio es posible si el diseño es lo suficientemente flexible y siempre que los materiales y componentes que lo constituyen permitan su reutilización (Miceli, 2016) o devolución al medio, lo que debe ser contemplado desde el nacimiento del proyecto. Cualquier sistema circular tiene como finalidad eliminar el factor "residuo" de su cadena. Por ello, el presente artículo concibe la posibilidad de reutilizar los componentes de la edificación una vez que esta haya alcanzado el fin de su vida útil, o bien devolverlos a la tierra. Estas son las estrategias de fin de vida o end-of-life que se plantean a continuación.

\section{ARQUITECTURA BIODEGRADABLE}

¿Qué sucede cuando la vida útil de un edificio culmina? ¿Adónde van sus materiales? La arquitectura biodegradable se presenta como una de las estrategias que plantea resolver el problema del fin de uso. Bio- proviene del griego y significa vida; degradable, de raíces latinas, implica que las cualidades inherentes del material se reduzcan o desgasten (Real Academia Española, s. f.). Por lo tanto, lo biodegradable, desde el punto de vista químico del material, es aquello que por acción biológica se degrada (Real Academia Española, s. f.). Todos los elementos pueden llegar a degradarse, sin significar que todos ellos sean biodegradables. Solo se consideran biodegradables los elementos que regresan a la naturaleza bajo la acción del metabolismo de microorganismos.

$\mathrm{Al}$ ver de cerca el acto constructivo de los animales, se evidencia que el humano no es el único animal arquitecto. En su lucha por la supervivencia, las construcciones animales se gobiernan por estrictas leyes de economía y eficacia (Pallasmaa, 2020). Los animales consiguen los materiales en el medio propio o en medios cercanos y, haciendo uso de diferentes métodos constructivos, configuran complejas estructuras habitables. Al final de su vida útil, estas "edificaciones" regresarán a la tierra sobre la que fueron concebidas gracias a la acción de microorganismos (véase la figura 3).

En la arquitectura también es posible replicar las características cíclicas de los procesos naturales donde las plantas crecen, mueren y se degradan para luego convertirse en un recurso (Sassi, 2006). El inspirarse en la naturaleza para crear productos y procesos que resuelvan problemas de diseño de manera sostenible se conoce como biomímesis o biomimética (Biomimicry Institute, 2021). Sus 

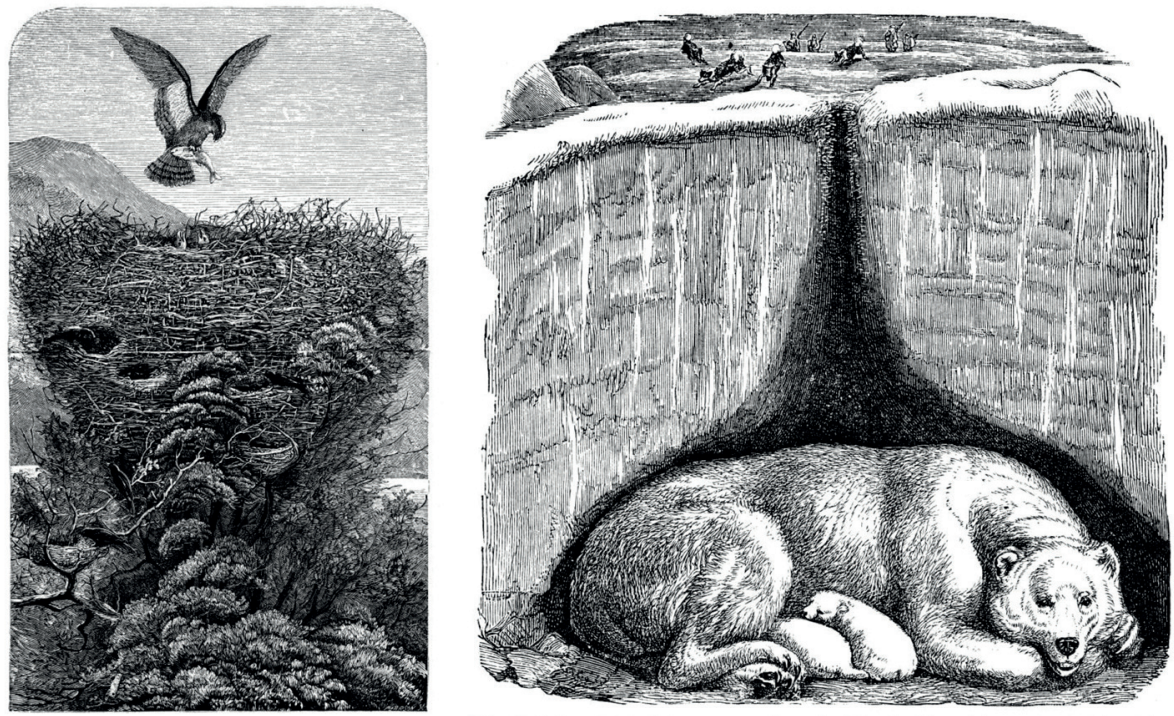

exponentes más cercanos suelen encontrarse en el campo de la arquitectura vernácula, ya que esta se define a partir del paisaje y cultura del lugar al que pertenece, por lo que se encuentra estrechamente ligada al medio (Burga, 2010).

Las diversas zonas geográficas del mundo cuentan con un tipo de arquitectura característica, tanto por sus métodos constructivos como por el uso del material. Ejemplo de esto es la arquitectura del desierto, con ciudades enteras hechas con ladrillos de barro en Yemen (véase la figura 4).

En las zonas boreales como Islandia, existía la casa langhus, que, al estar compuesta por estructura de madera cubierta por tierra y césped, aseguraba la protección contra el frío a los pueblos vikingos (véase la figura 5).

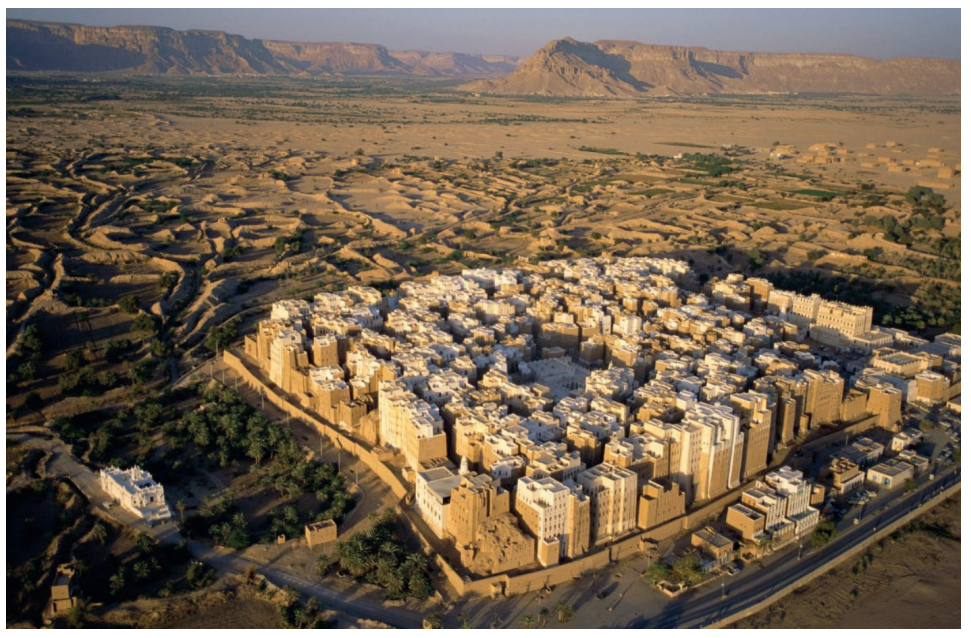

Figura 3 .

llustraciones del libro Animales arquitectos (2020), por Juhani Pallasmaa

Fuente:

Juhani Pallasmaa (2020)
Figura 4.

Valle de Hadramaut, Yemen

Fotografía:

Whitney Jones (2017) 
Figura 5.

Casas vikingas de jardín langhus, Islandia

Fuente:

"Casa comunal vikinga" (2015)

Figura 6.

Construcción ligera de caña y hoja de palma de la selva,

Pucallpa

Archivo fotográfico de las autoras

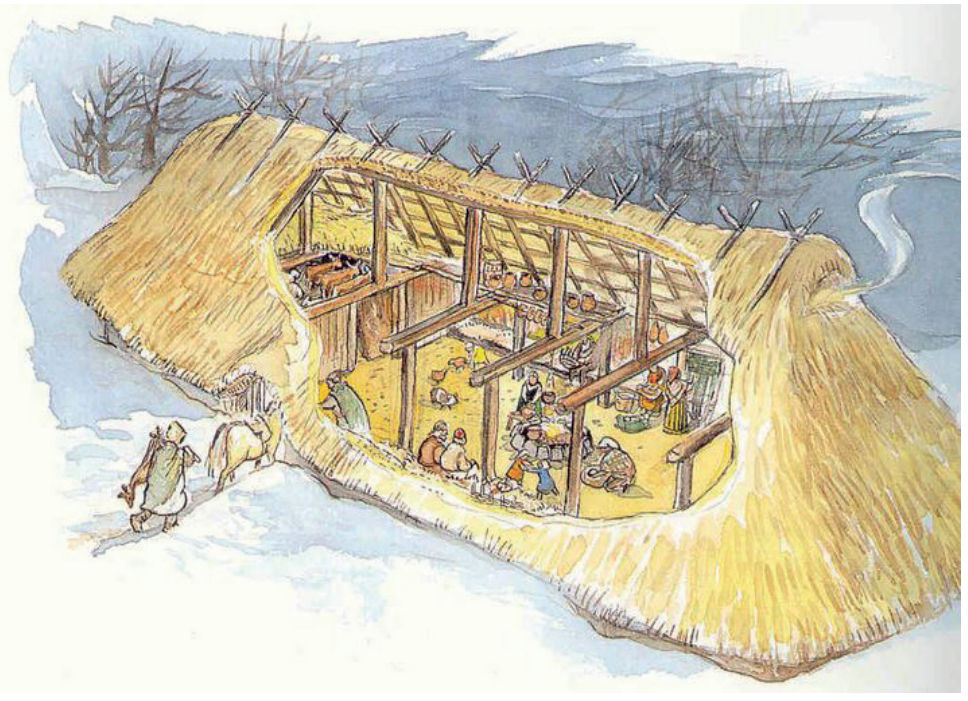

En las selvas tropicales de América del Sur son características las construcciones ligeras de cañas y hojas de palma (véase la figura 6) y en la sierra andina se usan materiales de importante masa térmica, como tapial, piedras e ichu (véase la figura 7). El listado podría seguir de manera indefinida, lo que nos lleva a concluir que la arquitectura del pasado trabajaba de manera armónica con cuatro factores: clima, geografía, materialidad y técnica constructiva.

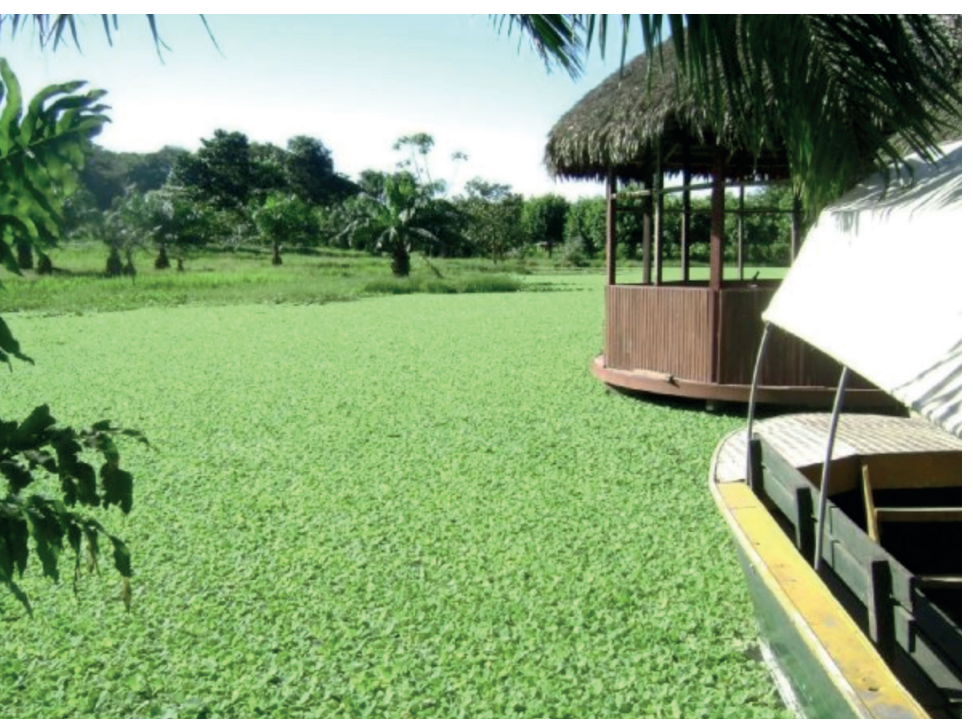




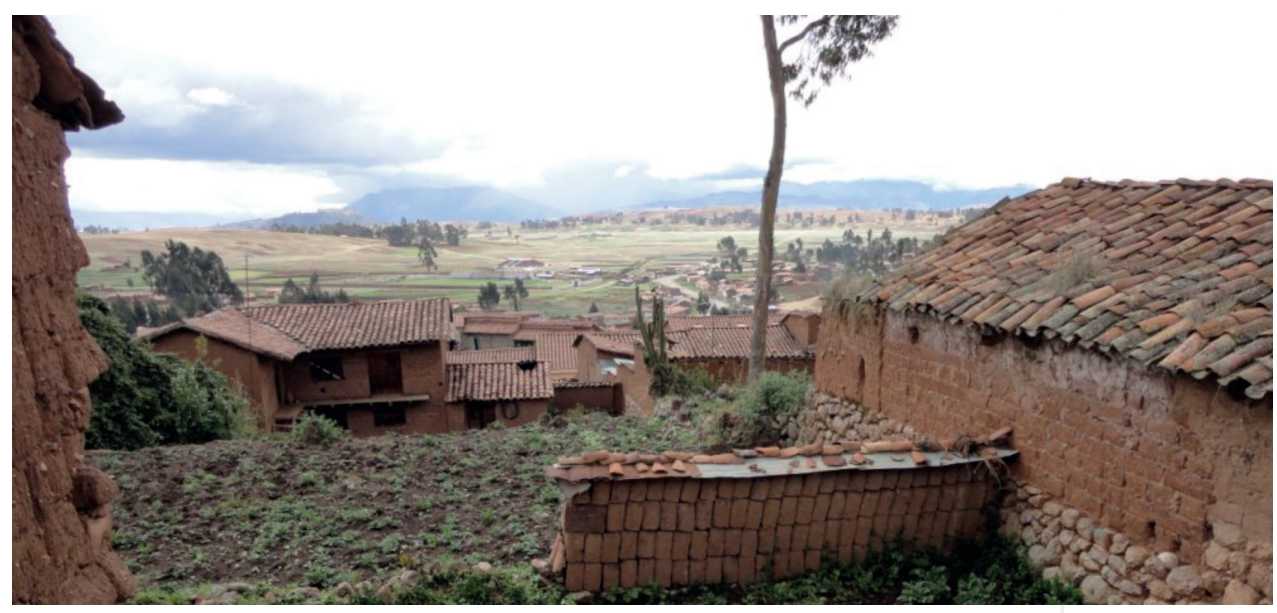

Los materiales tradicionales naturales son aquellos producidos con elementos y recursos propios del lugar, en algunos casos al pie de la obra. Estos requieren de baja tecnología para su producción. Miceli (2016) considera dentro de este grupo al adobe, papel, corcho, bambú, textiles, árboles, tejidos y piedra; siendo la madera, la piedra y la tierra los materiales más antiguos, los cuales se remontan a más de once mil años antes de Cristo (Miceli, 2016).

Retomando la construcción animal, como cita Pallasmaa (2020), Hansell divide los métodos constructivos en siete tipos: esculpido y excavado, apilamiento, moldeado, enrollado y plegado, pegado, tejido y, finalmente, cosido. Indica también que el método constructivo dependerá del material, y viceversa.

Al hacer un paralelismo con los métodos aplicados en la arquitectura vernácula peruana, se encuentra un criterio común: es el medio y sus características los que determinan los materiales y técnicas constructivas. El Perú cuenta con un territorio de diferenciadas características geográficas que, históricamente, ha marcado la manera de habitar el medio. Los materiales utilizados pueden clasificarse según su origen. El agua, tierra, arena y piedra, de origen mineral; la madera, palmas, fibra y hierbas, de origen vegetal; y los tientos para las amarras, pieles, cuernos, pezuñas, de origen animal (Burga, 2010).

A los materiales tradicionales naturales se han sumado en los últimos tiempos materiales innovadores aún en proceso de investigación y experimentación, pero con gran potencial. Los mycobricks son uno de ellos; son un material constructivo natural biodegradable, hechos a base de la parte vegetativa de los hongos, llamada micelio (véase las figuras 8, 9 y 10) (Karimjee, 2014).

\section{Figura 7}

Construcción de tapial, piedra e ichu, Urubamba, Cusco

Archivo fotográfico de las autoras 
Figura 8. Estructura de un hongo

Fuente: Carles i Font (2006)

Figura 9 .

Gráfico de huella ecológica en materiales tradicionales

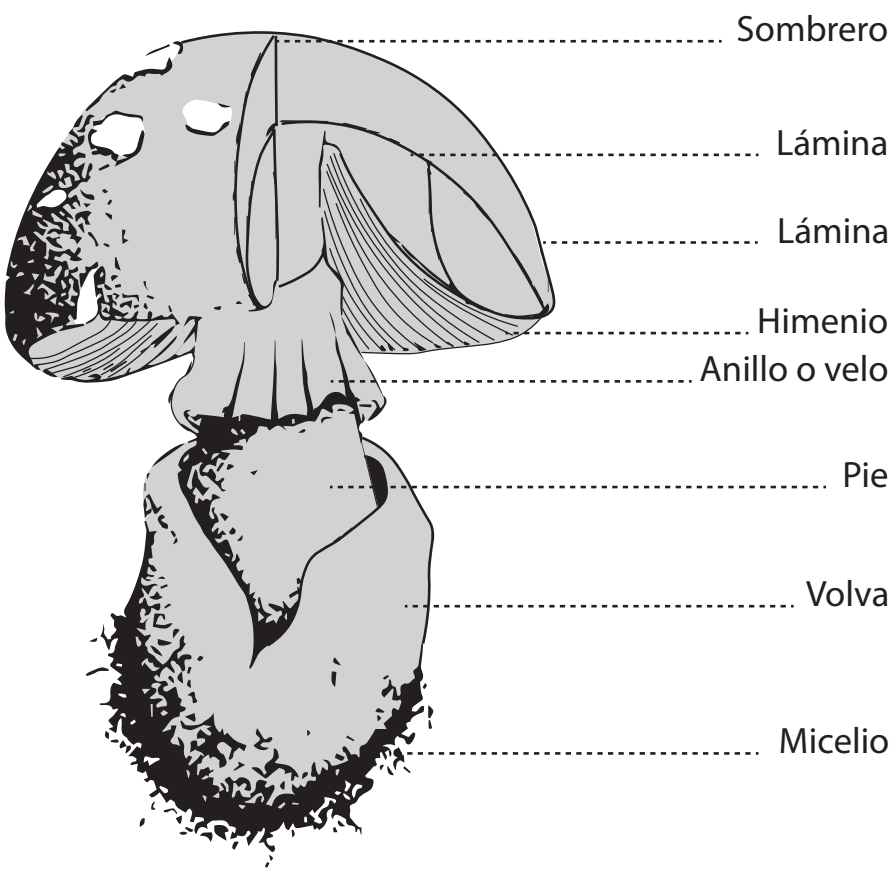

BAJA TECNOLOGÍA

Adobe

Áridos

Papel

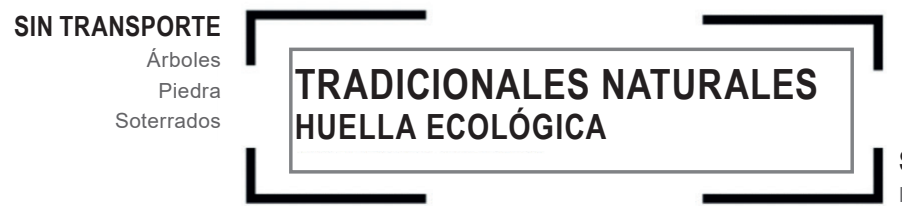

SIN MÁQUINAS

Bambú

Entretejido-telas

Se producen con baja tecnología

- No emplea maquinaria para su elaboración

- No necesitan transporte

- Uso de recursos del lugar

- Forma de medición: capacidad de carga 


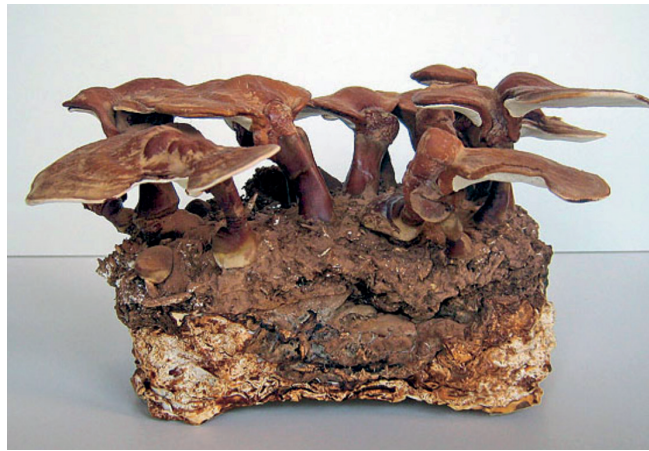

Estos no contienen componentes tóxicos, son ignífugos, resistentes al moho y al agua, y poseen una alta inercia térmica. En el 2012, el artista Philip Ross logró verificar y patentar mediante pruebas de laboratorio que los mycobricks son más resistentes que el concreto. Estas características implican una importante oportunidad y una nueva perspectiva a la hora de entender la arquitectura ambiental (véase la figura 11).

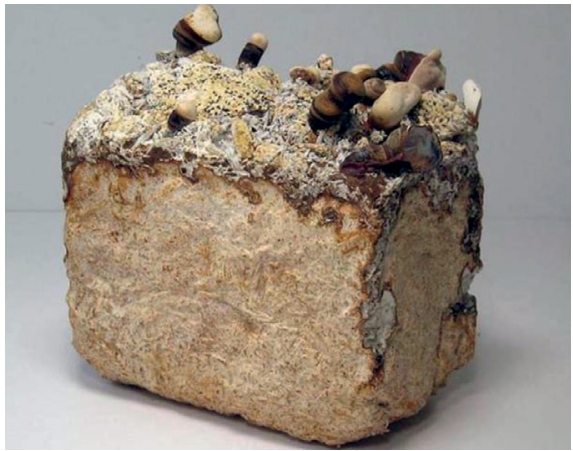

Figura 10.

Ladrillo de micelio

Fotografía:

Boyer (2017)

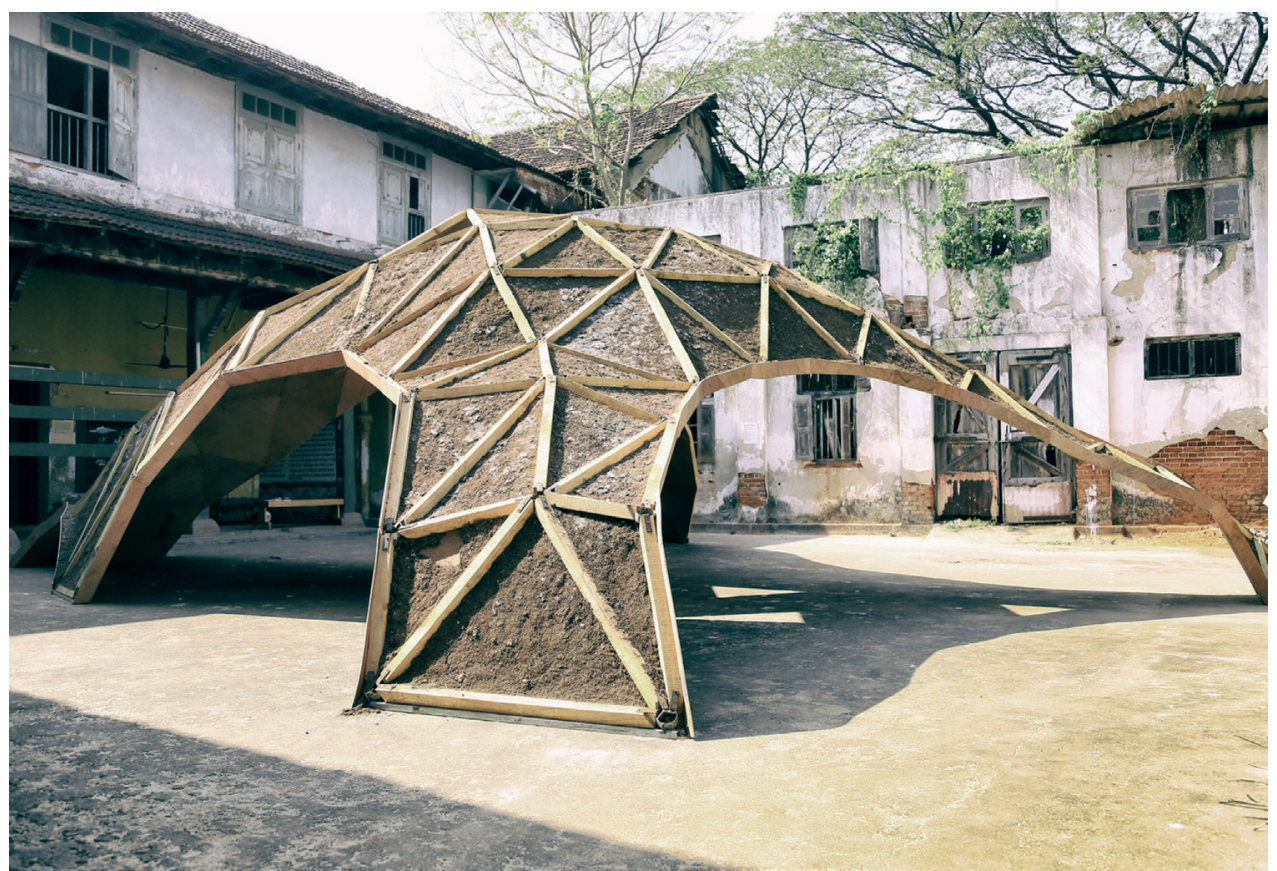


Figura 11 Edificación hecha con mycobricks

Fuente: Syed (2017)
(1.)

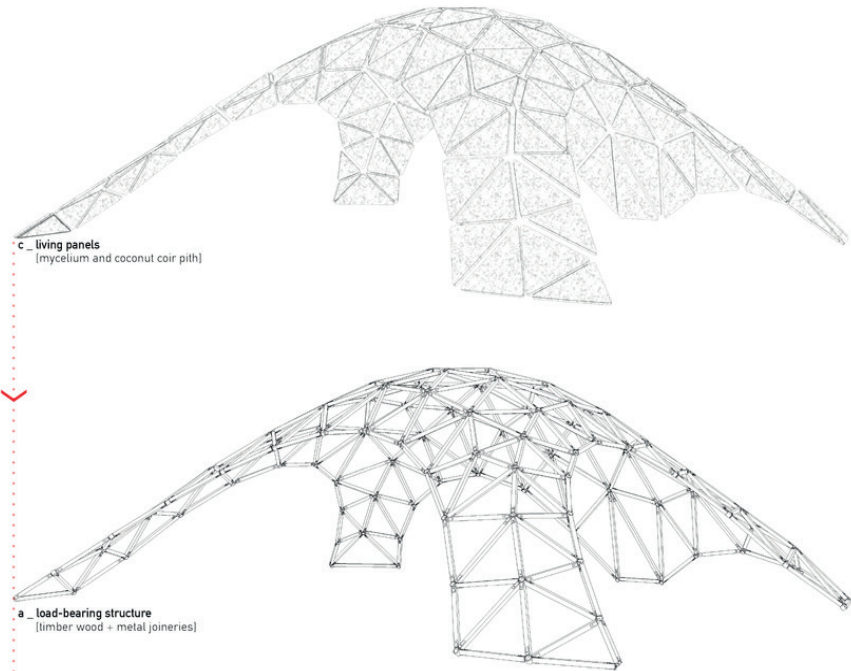

(3.)

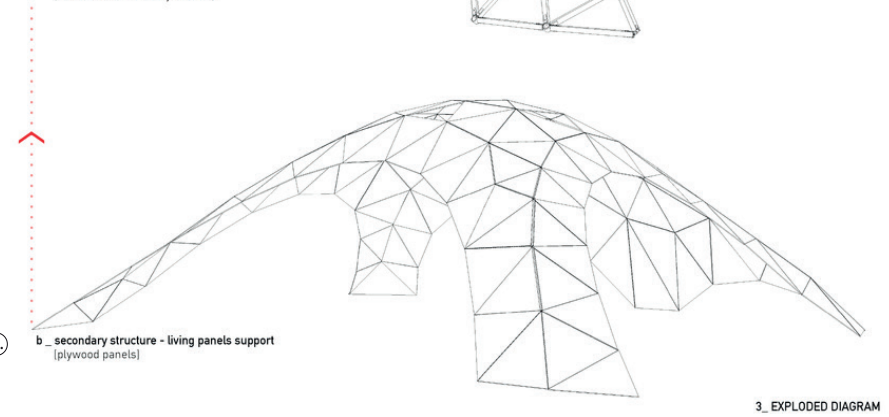

1. Paneles vivos (médula de fibra de coco)

2. Estructura portante (madera + uniones de metal)

3. Estructura secundaria - soporte de los paneles vivos (paneles de madera contrapacada)

No solo permiten un fin de vida saludable, sino también que, al llegar a su término, hacen posible que los componentes del edificio puedan contribuir a regenerar el territorio y mejorar su calidad ambiental, por medio de la biorremediación (Karimjee, 2014).

Entender la arquitectura como un objeto compostable, en donde los deshechos son algo positivo para el medio ambiente, y se brindan maneras de rehabilitarlo a través de estrategias sostenibles para el fin de vida de un edificio (Karimjee, 2014), permite concebir a la edificación como un organismo vivo perteneciente a un sistema mayor. En este, los materiales que lo constituyen se convierten en aliados del diseño arquitectónico sostenible (Miceli, 2016).

Otros nuevos materiales biodegradables son el finite, bloques hechos con arena del desierto y aglutinantes orgánicos, desarrollado por estudiantes del 
Imperial College de Londres ${ }^{1}$; el linóleo, fabricado con aceite de linaza, resina natural, polvo de corcho molido, harina de madera y polvo de piedra caliza; bioplásticos hechos de soya, por ahora limitados al uso en arquitectura efímera y arte; así como el MDF, hecho con resinas derivadas del almidón de papa, desarrollado por la Universidad de Leicester (Thorns, 2018a, 2018b).

En el marco de la arquitectura biodegradable, los principales materiales que la componen, sean tradicionales o innovadores, deben cumplir con la condición de poder retornar naturalmente a la tierra al final de su vida útil, sin generar un impacto nocivo en ella. Sassi (2006) define teóricamente el concepto de edificios biodegradables en torno a su relación con la naturaleza, y afirma que su implementación práctica puede contribuir a una agenda integral para el diseño sostenible.

Así, la arquitectura biodegradable considera en simultáneo la construcción y la demolición amigable (Karimjee, 2014), entendiéndolas como un binomio, en donde la demolición se ve traducida en la reabsorción de sus componentes. Estos componentes biodegradables no habrán de dejar huella alguna de su existencia previa, puesto que regresarán naturalmente a la tierra, pudiendo incluso significar un beneficio para ella (véase la figura 12).

Figura 12

Edificación hecha con mycobricks (mycotexture)

Fotografía: Jackie Caradonio (2014a, 2014b)
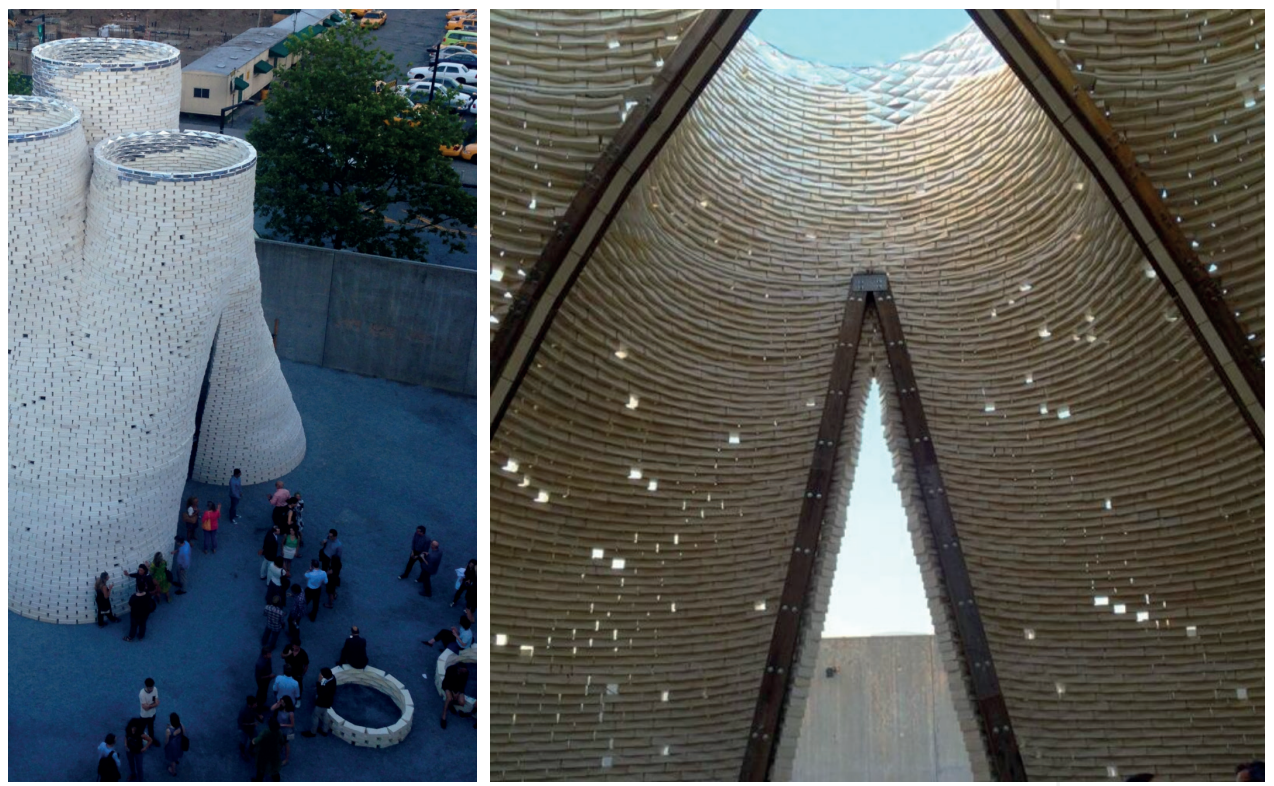

1 El finite, creado por los estudiantes Carolyn Tam, Hamza Oza y Matteo Maccario, tiene la misma resistencia que los ladrillos y concreto utilizado en construcciones residenciales, con la diferencia de que este se puede moldear y reutilizar durante múltiples ciclos de vida, o simplemente dejar que se biodegrade de manera segura. Para más información, véase Evanson (2018). 


\section{ARQUITECTURA PARA EL DESENSAMBLE}

¿Qué sucede cuando después de una serie de adaptaciones el edificio ya no corresponde a las dinámicas y necesidades de los usuarios? ¿Adónde van los componentes que lo conforman y que se encuentren en buen estado? El concepto de desensamble implica poder desunir o separar las piezas ensambladas (Real Academia Española, s. f.). Este tipo de diseño se presenta como la otra estrategia de fin de vida útil que permite generar una segunda vida a los componentes de las edificaciones. En esta, como lo indica su nombre, se propone la posibilidad de descomponer y desarmar el proyecto en piezas para poder reutilizarlas en una nueva edificación.

El concepto está vinculado al diseño de productos, como contraparte al "diseño para el ensamble" (design for assembly, DFA). Los procesos de ensamble y desensamble (armado y desarmado) son distintos; las decisiones de diseño que simplifican el primer proceso no necesariamente facilitan el segundo, que se encuentra más centrado en procesos de reparación, adaptación y reúso (Denis et al., 2018).

Esta visión cíclica del medio construido tiene múltiples beneficios ambientales y económicos. Reduce la cantidad de recursos y desperdicios del proyecto, y responde a la demanda de un mercado que se encuentra en constante cambio. Por ende, su valor de reventa se mantiene, haciendo la propiedad más rentable a largo plazo (Guy et al., 2008; Kwak et al., 2009).

A pesar de los beneficios que podría significar, hoy en día los principales métodos de fabricación de componentes suelen ser vaciados in situ. El trabajar con uniones húmedas y mezclando las distintas capas del edificio (instalaciones, recubrimientos, etcétera) dificulta e impide el desarmado y recuperación de los componentes al final de su vida útil (Salama, 2017), una pérdida en los aspectos económico y ecológico.

Aunque el concepto de desensamble no se encuentre difundido en las técnicas constructivas actuales, en la historia se puede resaltar una serie de casos que mediante un diseño flexible, modular y despiezable han logrado generar escenarios de fin de uso sin llegar a la obsolescencia.

Dentro de la tradición filosófica japonesa, la forma en que el ser humano establece una relación dinámica con el entorno es lo que estructura su existencia (Berque, 2009). Esto se ve reflejado en el linaje constructivo vernáculo japonés. Las construcciones suelen separar la estructura del edificio de su envolvente (planos divisorios no estructurales) (Crowther, 1999), lo que les permite mantener flexibilidad espacial, la remoción de sus piezas y reconstrucción (Kikutake, 1995). Esta flexibilidad estructural hace posible que los cerramientos puedan intercambiarse de acuerdo con el clima y la relación de la vivienda con el medio (véase la figura 13). 
(1.)

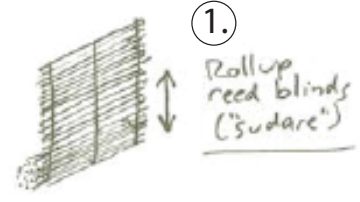

(2.)

\section{Solid wood} sliding storm. forsecurity atnight, and in inclemert weather

Translucest sliding paper door $\left(\right.$ shoj $\left.i{ }^{*}\right)$
allows light in. allows light in?
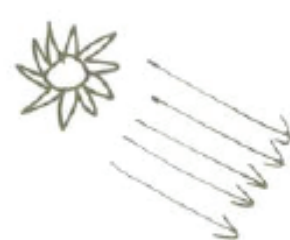

8.

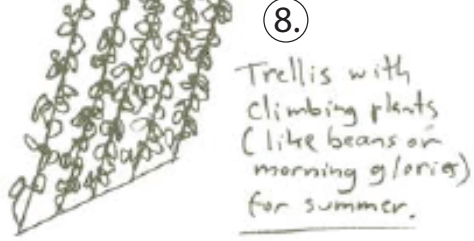

1. Persianas enrolladas

2. Puerta corrediza de madera sólida para seguridad en la noche y para proteger del clima

3. Puerta corrediza traslúcida (shoji), permite el ingreso de luz
4. Gradación de sombras

5. El piso de la veranda es reflectante

6. Los mats de tatami reflejan una luz cálida y difusa

7. Puerta corrediza opaca de papel (fusuma)

8. Enrejado con enredaderas
Figura 13.

Modulación

y despiece de

los distintos

ingresos de luz

en la arquitectura

vernácula japonesa

Fuente:

Angen (2013) 
Los principios de la arquitectura vernácula en Japón influencian de manera directa los del movimiento metabolista. Este rescata los principios de flexibilidad espacial por medio de elementos montables y desmontables (Oshima, 2012). En ambos casos, la flexibilidad que admite un sistema desarmable permite al edificio variar en relación con los cambios sociales y ambientales, extender su vida útil y evitar la obsolescencia de sus componentes.

Dentro de la tradición constructiva occidental, un ejemplo claro de construcción para el desensamble fueron las cabañas de madera construidas en las colonias inglesas. Como cita Crowther en "Design for Disassembly: An Architectural Strategy" (1999), en 1624, los británicos exportaron el despiece de casas prefabricadas de madera a los nuevos territorios. Los diseños de las cabañas hacían uso de tecnologías de ensamblaje secas, con la finalidad de ahorrar en material y energía. Esto les daba la posibilidad de trasladarse con sus viviendas, en caso de que el asentamiento tuviese que movilizarse (p. 28).

En el siglo xix, con el desarrollo de las estructuras de acero, se plantearon edificios efímeros. El Palacio de Cristal en Londres (véase la figura 15), por Joseph Paxton (Durmisevic, 2010), o la Torre Eiffel (véase la figura 16) son ejemplos de esto. Así se marcó un punto de inicio para otros proyectos con las mismas lógicas constructivas, tales como el Centre Pompidou (véase la figura 17) o el Shanghai Bank (Salama, 2017).

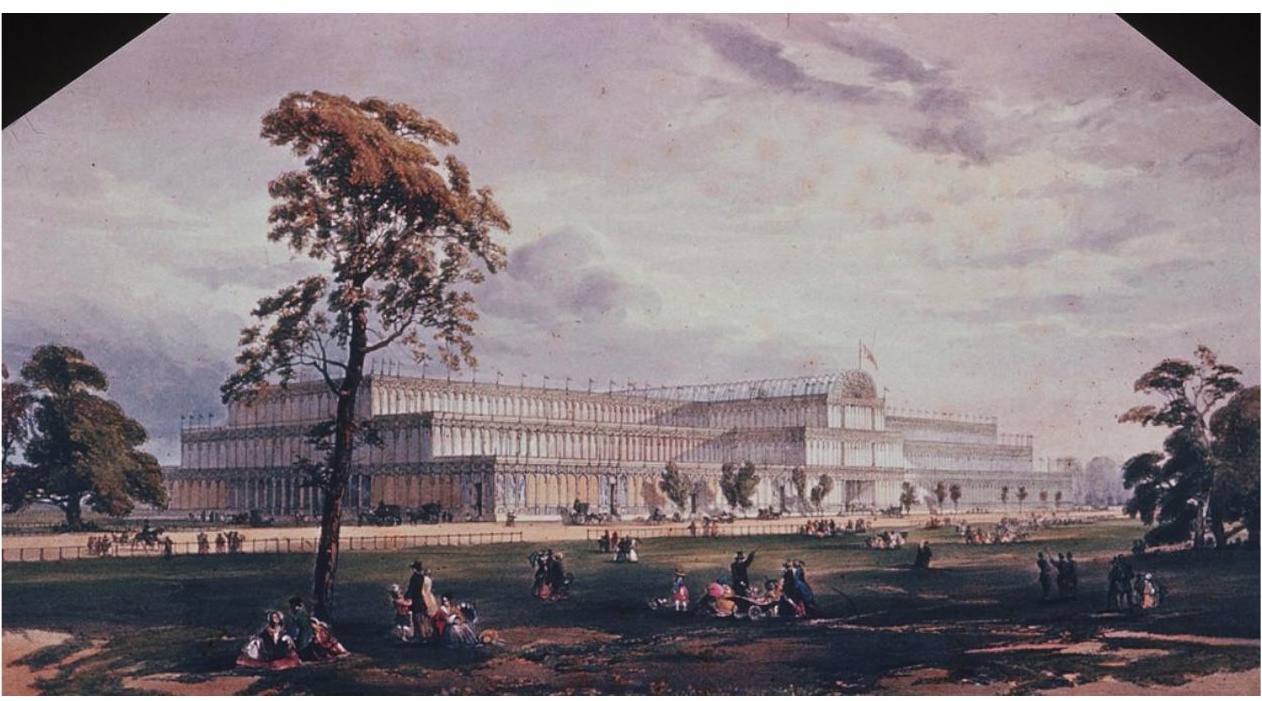




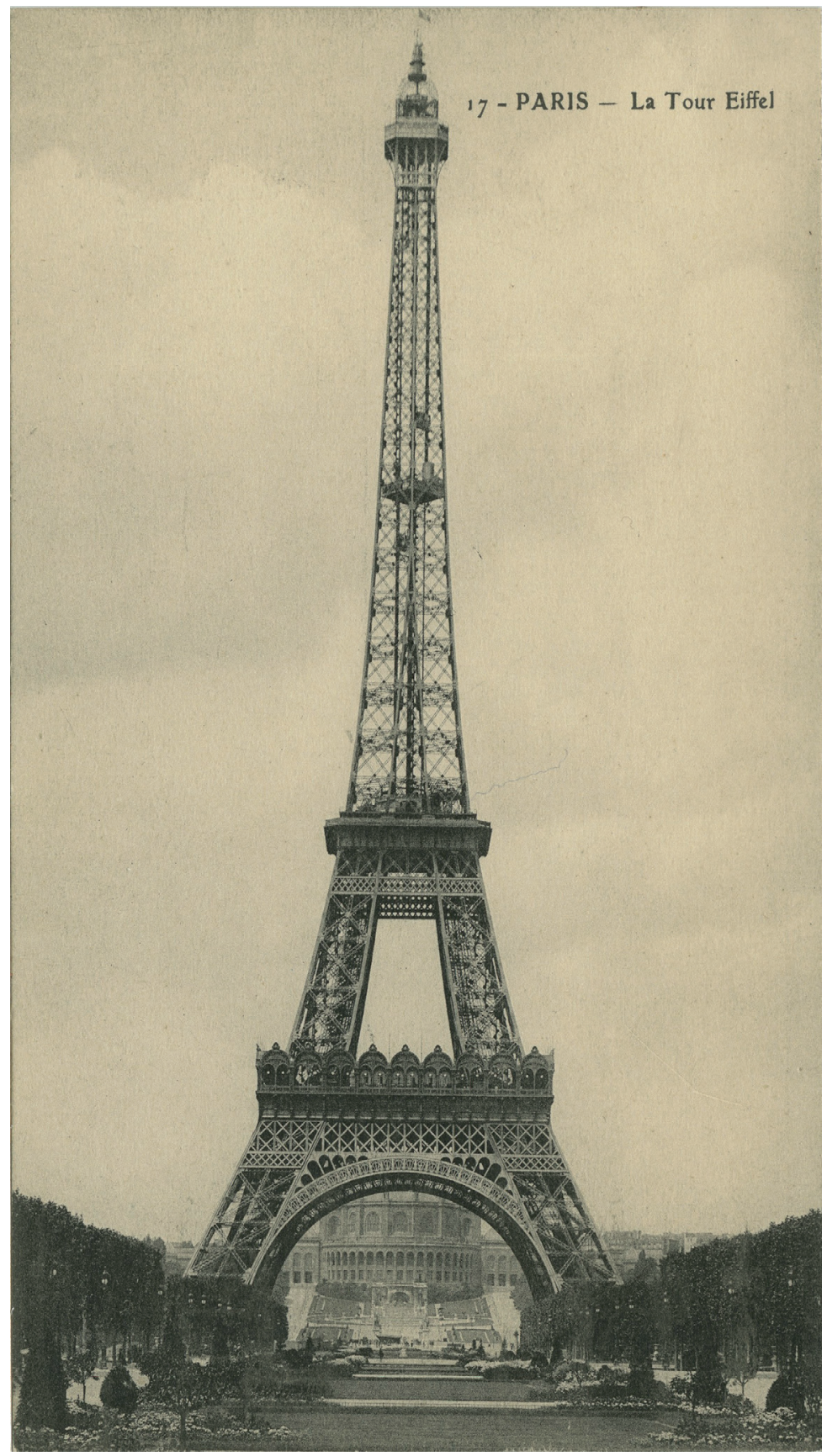

Figura 15.

Torre Eiffel en París, por Gustave Eiffel

(1887)

Fuente:

17 -- PARIS -- La Tour Eiffel (ca. 1907-1914) 
Figura 16

Centre Pompidou, por

Renzo Piano (1977)

Fuente:

Piano (1977)

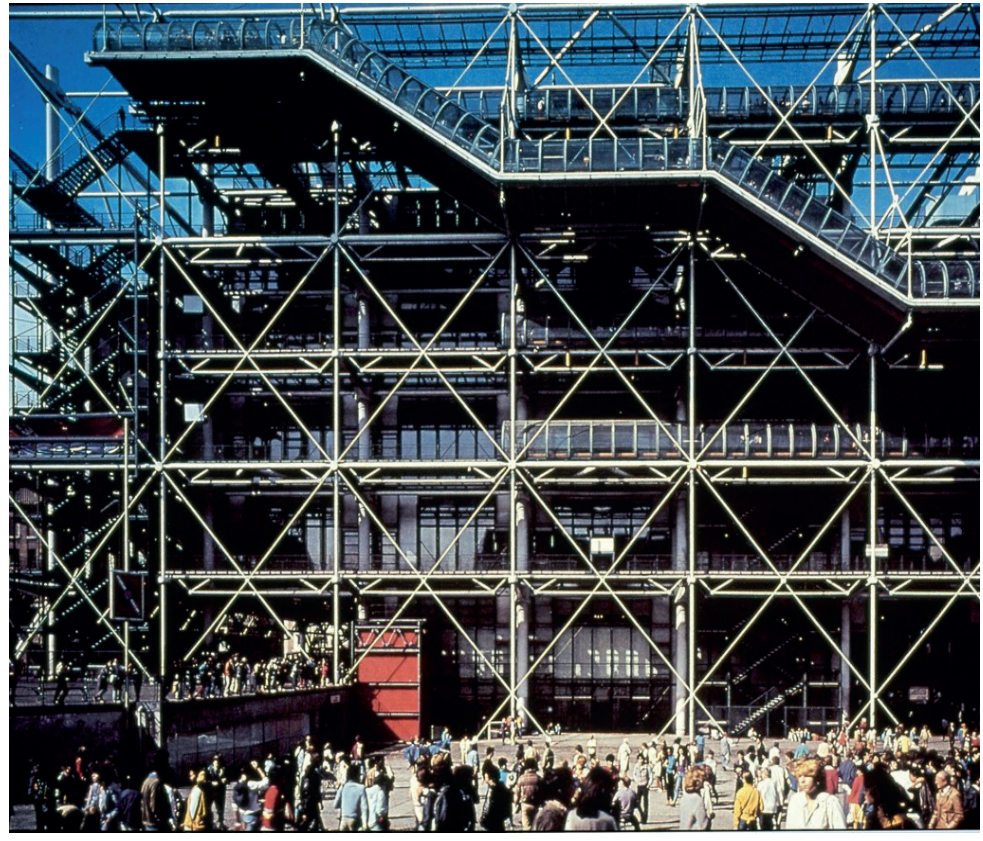

Todos estos referentes tienen como característica común la flexibilidad espacial y la posibilidad de ser desmontados al final de su vida útil. Para lograr un diseño que cumpla con estas características, se requiere tomar las decisiones pertinentes al momento de diseñar y considerar los posibles usos al terminar el ciclo (Kwak et al., 2009).

De esta manera, se deben definir los tipos de materiales, con base en su tiempo de vida, resistencia y ligereza. La separación entre estructura y envolvente, así como el uso de un módulo constructivo estándar, son determinantes para alcanzar una mayor eficiencia (Crowther, 1999). Además, el diseño de las uniones por medio de tecnología seca, sin procesos químicos, asegurará su capacidad de desarmarse (Chica et al., 2010). Por último, lo que determinará su éxito es la planificación durante la etapa de diseño de las secuencias de ensamble y desensamble en todas las escalas del proyecto (Crowther, 1999; Guy et al., 2008).

Brand (1994) aplica el principio de las seis "S" de stuff, space plan, services, skin, structure, site (mobiliario, disposición del espacio, servicios, piel, estructura y lugar), para disgregar las distintas escalas del proyecto. Estas categorías tienen distintos tiempos de vida y, por lo tanto, su manutención o reemplazo responderá a distintos ciclos. Como estrategia de diseño, se plantea proyectarlas en capas autónomas, facilitando el mantenimiento y cambio de componentes (véase la figura 18) (Guy et al., 2008). 


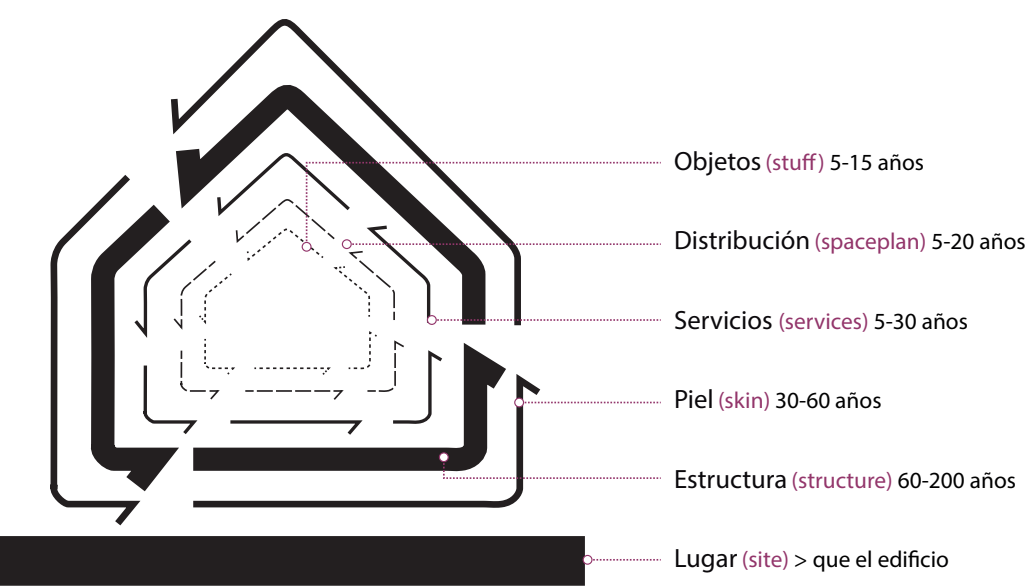

Así se logra que, llegado el final del tiempo de vida de la edificación, sus componentes se descompongan en grupos y clasifiquen en reusables, reciclables y desechos (Kwak et al., 2009). De esta manera regresan al ciclo en nuevos proyectos y empiezan una segunda vida.

\section{CONCLUSIONES}

Aferrarse a la idea del edificio eterno es una negación perjudicial para la práctica de la arquitectura sostenible. Desde la profesión es necesario asumir que la arquitectura, al igual que todas las estructuras sociales y ambientales, no se escapa de su inminente característica de ser perecible y, por lo tanto, se debe contemplar su fin de uso desde la etapa de diseño, junto con las estrategias que lo harán sostenible. Estas abarcan desde la prolongación de su vida útil por medio de la flexibilidad, la capacidad de descomponerse y rearmarse, biodegradarse o reciclarse. La respuesta a un medio cambiante deberá darse a través de estrategias cambiantes.

Aunque prolongar el tiempo de vida útil del edificio resulta la estrategia primaria, no recomendamos estandarizar los tiempos de uso; por el contrario, a través de la consideración de múltiples variables, tales como los materiales, tipo de uso, consumo energético, costos de mantenimiento, arraigo cultural, entre otros, se lograría generar una valoración que permita determinar el tiempo de uso cíclico, idóneo y específico para cada proyecto.

Las estrategias planteadas en el presente artículo son presentadas originalmente como contrapartes; sin embargo, terminan siendo complementarias. Lo primero es entender que, tanto en la arquitectura biodegradable como en la arquitectura del desensamble, la totalidad de sus componentes permanentes no podrían llegar a ser absolutamente desmontables ni absolutamente biodegradables; es por ello que planteamos la posibilidad de entenderlas como
Figura 17.

Diagrama de las seis "S", de Stewart Brand 
complementarias: es decir que una parte de los componentes regrese a la tierra mediante la degradación de microorganismos, mientras que otra parte pueda ser reutilizada en un nuevo proyecto.

Los ejemplos listados en el presente artículo pertenecen principalmente a la arquitectura vernácula y a una nueva arquitectura que podría considerarse de carácter inusual; sin embargo, los conceptos de desensamble y arquitectura biodegradable no son ajenos a la arquitectura contemporánea convencional, ya que toda edificación posee un ciclo de vida tangible, pudiendo, a partir del uso de programas pertinentes, evaluar cuál es el fin de vida que le espera a las construcciones que encontramos ya edificadas en nuestro medio. Consideramos dicho tema de gran interés y que puede ser profundizado en investigaciones futuras.

Empezamos este artículo preguntándonos adónde van los edificios cuando mueren. Dar una respuesta única sería un acto contradictorio, pues los edificios no son elementos compuestos por una pieza única, sino que están conformados por un conjunto de componentes, en donde cada uno de ellos puede llegar a tener un destino diferente. Lo importante es asegurar desde la arquitectura que cada uno de esos destinos resulten en el inicio de una nueva vida y que sean producto de un acto reflexivo en torno a la sostenibilidad.

\section{REFERENCIAS}

Aircrew Lifestyle. (s. f.). Casa del Oidor y Catedral de Lima [Fotografía]. http://aircrewlifestyle.es/48-horas-en-lima-capital-de-contrastes -y-continua-evolucion/casa-del-oidor-y-catedral-de-lima/

Angen, C. (2013). Concept and Technique: How Traditional Japanese Architecture Can Contribute to Contemporary Sustainable Design Practices. Environmental Studies Honors Papers, 10. https://digitalcommons.conncoll.edu/cgi/ viewcontent. cgi?article $=1008 \&$ context=envirohp

Berque, A. (2009). El pensamiento paisajero. Biblioteca Nueva.

Biomimicry Institute. (2021). Understanding Biomimicry. https://biomimicry.org/ what-is-biomimicry/

Boyer, M. (1 de febrero del 2017). Philip Ross Molds Fast-Growing Fungi Into Mushroom Building Bricks That Are Stronger than Concrete. INHABITAT. https://inhabitat.com/phillip-ross-molds-fast-growing-fungi-into-mushroombuilding-bricks-that-are-stronger-than-concrete/

Brand, S. (1994). How Buildings Learn. The Penguin Group.

Burga, J. (2010). Arquitectura vernácula peruana. Un análisis tipológico. Colegio de Arquitectos del Perú.

Caradonio,J.[@jackiecaradonio].(26dejuniodel2014a).Privatepreviewofthissummer's Warm-Up installation at @MoMAPS1 \#HyFi \#theliving [Fotografía adjunta]. Twitter. https://twitter.com/jackiecaradonio/status/482365355013074944/ photo/1 
Caradonio, J. [@jackiecaradonio]. (26 de junio del 2014b). The cathedral-like interiors of \#HyFi @MoMAPS1. \#theliving [Fotografía adjunta]. Twitter. https://pbs. twimg.com/media/BrGxXX5CIAA_fXP?format=jpg\&name $=900 \times 900$

Carles i Font, J. (2006). Características de los hongos. El mundo de los hongos. https:/lusuaris.tinet.cat/fongs/caractercas.htm

Casa comunal vikinga. (31 de julio del 2015). La Comunidad del Roble. https:// lacomunidaddelroble.wordpress.com/2015/07/31/casa-comunalvikinga-longhouse-langhus/

Chau, C., Xu, J., Leung, T., y Ng, W. (2016). Evaluation of the Impacts of End-of-Life Management Strategies for Deconstruction of a High-rise Concrete Framed Office Building. Applied Energy, 185(Part 2), 1595-1603.

Chica, J., Apraiz, I., Elguezabal, P., Rips, M., Sánchez, V., y Tellado, B. (2010). KUBIK: Open Building Approach for the Construction of an Unique Experimental Facility Aimed to Improve Energy Efficiency in Buildings. En J. Chica, P. Elguezabal, S. Meno y A. Amundarain (Eds.), 16th International Conference on "Open and Sustainable Building" (pp. 39-50). Tecnalia.

Crowther, P. (1999). Design for Disassembly: An Architectural Strategy for Sustainability. En M. Ganis (Ed.), Design for Sustainability (pp. 27-33). Queensland University of Technology.

Da Silva, T. (1998). Predicción de la vida útil de forjados unidireccionales de hormigón mediante modelos matemáticos de deterioro. Escuela Técnica de Ingenieros de Caminos, Canales y Puertos de Barcelona.

Decreto Supremo 015-2015-Vivienda [Ministerio de Vivienda]. Código Técnico de Construcción Sostenible. 28 de agosto del 2015.

Denis, F., Vandervaeren, C., y De Temmerman, N. (2018). Using Network Analysis and BIM to Quantify the Impact of Design for Disassembly. Buildings, 8(113), 2-22. doi:10.3390/buildings8080113

17 -- PARIS -- La Tour Eiffel [Fotografía]. (ca. 1907-1914). https://library-artstor-org. ezproxy.ulima.edu.pe/asset/SS35428_35428_20081367

Directiva 002-2014-EF/51.01 [Ministerio de Economía y Finanzas]. Metodología para la modificación de la vida útil de los edificios. Revaluación de edificios y terrenos, identificación e incorporación de edificios y terrenos de administración funcional y reclasificación de propiedades de inversión en las entidades gubernamentales. 19 de mayo del 2014.

Dodoo, A., Gustavsson, L., y Sathre, R. (2009). Carbon Implications of End-ofLife Management of Building Materials. Resources, Conservation and Recycling, 53(5), 276-286.

Durmisevic, E. (2010). Green Design and Assembly of Buildings and Systems. VDM Verlag Dr. Müller.

Evanson, D. (15 de marzo del 2018). Could These Seven Student Inventions Be the Next Big Thing? Imperial College London. https://www.imperial.ac.uk/ news/185335/could-these-seven-student-inventions-next/ 
Fay, R., Treloar, G., e lyer-Raniga, U. (2000). Life-Cycle Energy Analysis of Buildings: a Case Study. Building Research \& Information, 28(1), 31-41.

Gardner, H., García, J., Hasik, V., Olinzock, M., Banawi, A. y Bilek, M. (2019). Materials Life Cycle Assessment of a Living Building. Procedia CIRP, 80, 458-463.

Guy, B., Ciarimboli, N., y Hendrickson, K. (2008). DfD. Design for Disassembly in the Built Environment: A Guide to Closed-Lood Design and Building. Hamer Center.

Jones, W. (14 de marzo del 2017). Shibam - Skyscraper Fortress Built from Mud. Cfile.Daily. https://cfileonline.org/architecture-shibam-skyscraper-fortressbuilt-from-mud/

Karimjee, M. (2014). Biodegradable Architecture, Finite Construction for Endless Futures [Tesis de maestría no publicada]. Azrieli School of Architecture and Urbanism.

Kikutake, K. (1995). On the Notion of Replaceability. World Architecture, 33, 26-27.

Kotler, P., y Armstrong, G. (2003). Fundamentos de marketing. Pearson Educación.

Kwak, M., Hong, Y., y Cho, N. (2009). Eco-Architecture Analysis for End-of-Life Decision Making. International Journal of Production Research, 47(22), 6233-6259.

Lamb, C., Hair, J., y McDaniel, C. (2006). Fundamentos de marketing. Thomson.

Lavagna, M., Arena, M., Giovanni, D., y Zanchi, M. (2014). Le strutture temporanee per Expo Milano 2015: valutazione ambientale e soluzioni per la gestione del fine vita. Techne, Journal of Technology for Architecture and Environment, 7, 171-177.

León, J. (26 de agosto del 2017). En Lima se generan 19 mil toneladas de desmonte al día y el $70 \%$ va al mar o ríos. El Comercio. https://elcomercio.pe/lima/ sucesos/lima-generan-19-mil-toneladas-desmonte-dia-70-mar-rios-noticia453274-noticial

Miceli, A. (2016). Arquitectura sustentable. Más que una nueva tendencia, una necesidad. Ediciones de la U.

Ministerio del Ambiente. (2012a). Gestión ambiental de residuos sólidos en el Perú. XV Reunión Anual de Gestión de Residuos Sólidos. Edición del Autor.

Ministerio del Ambiente. (2012b). Inventario Nacional de Gases de Efecto Invernadero (INGEI). Edición del Autor.

Ministerio del Ambiente. (2015). Residuos sólidos. Estadísticas. https://sinia.minam. gob.pe/temas/residuos-solidos/estadisticas/

Norma EM.110: Confort Térmico y Lumínico con Eficiencia Energética. (13 de mayo del 2014). Diario oficial El Peruano, pp. 523069-523118. https://cdn-web. construccion.org/normas/rne2012/rne2006/files/titulo3/04_EM/DS0062014_EM.110.pdf 
Organización Internacional de Normalización. (2006). Gestión ambiental. Análisis del ciclo de vida. Principios y marco de referencia (ISO 14040). https://www. iso.org/obp/uittiso:std:iso:14040:ed-2:v1:es

Oshima, K. (2012). Metabolist Trajectories. Log, 24, 28-32.

Pallasmaa, J. (2020). Animales arquitectos. Gustavo Gili.

Paxton, J. (1850-1851). London: Crystal Palace Gen [Great Exhibition of 1851]. https://library-artstor-org.ezproxy.ulima.edu.pe/asset/ARTSTOR_103_ 41822000006625

Pérez, L. (2010). Vida útil residual de estructuras de hormigón armado afectadas por corrosión. Universidad Politécnica de Madrid.

Petrovic, B., Myhren, J., Zhang, X., Wallhagen, M., y Eriksson, O. (2019). Life Cycle Assessment of Building Materials for a Single-Family House in Sweden. Energy Procedia, 158, 3547-3552.

Piano, R. (1977). París: Pompidou Center. https://library-artstor-org.ezproxy.ulima. edu.pe/asset/ARTSTOR_103_41822003437694

Real Academia Española. (s. f.). Bio-. En Diccionario de la Real Academia Española. Recuperado el 9 de junio del 2019 de https://dle.rae.es/bio-?m=form

Real Academia Española. (s. f.). Biodegradable. En Diccionario de la Real Academia Española. Recuperado el 9 de junio del 2019 de https://dle.rae.es/ biodegradable

Real Academia Española. (s. f.). Degradable. En Diccionario de la Real Academia Española. Recuperado el 9 de junio del 2019 de https://dle.rae.es/ degradable?m=form

Real Academia Española. (s. f.). Desensamblar. En Diccionario de la Real Academia Española. Recuperado el 9 de junio del 2019 de https://dle.rae.es/ desensamblar? $m=$ form

Ros, C. (20 de marzo del 2020). Arquitectura animal. Arquitectura y Diseño. https:/l www.arquitecturaydiseno.es/pasion-eco/libro-para-aprender-comoanimales-viven-casas-muy-buena-arquitectura_3864

Salama, W. (2017). Design of Concrete Buildings for Disassembly: An Explorative Review. International Journal of Sustainable Built Environment, 6(2), 617-635.

Sassi, P. (2006). Biodegradable Building. En C. A. Brebbia (Ed.), Design and Nature III (pp. 91-102). WIT, Transactions on Ecology and the Environment, vol. 87.

Syed, S. (28 de septiembre del 2017). Este pabellón "vive y muere" para hacer una crítica a la sostenibilidad. Archdaily. https://www.archdaily.pe/pe/880342/ este-pabellon-vive-y-muere-para-hacer-una-critica-a-la-sostenibilidad

Thiébat, F. (2013). Progettazione sostenibile nel ciclo di vita. Techne, Journal of Technology for Architecture and Environment, 5, 177-183. 
Thorns, E. (29deabrildel2018a). ¿Próxima crisisdelasustentabilidad? Estamosusando tanta arena que pronto podría acabarse. Archdaily. https://www.archdaily. pe/pe/892939/la-proxima-crisis-de-sustentabilidad-los-seres-humanosestan-usando-tanta-arena-que-de-hecho-podriamos-extinguirnos

Thorns, E. (27 de mayo del 2018b). 8 materiales biodegradables que la industria de la construcción necesita conocer. Archdaily. https://www.archdaily. co/co/893955/8-materiales-biodegradables-que-la-industria-de-laconstruccion-necesita-conocer 